\title{
A CATEGORIA CIDADANIA NA BNCC DE GEOGRAFIA: AS FINALIDADES FORMATIVAS NO PROCESSO DE RECOMPOSIÇÃO BURGUESA
}

\section{La categoría ciudadanía en la geografía de la BNCC: los propósitos formativos en el proceso de recomposición burguesa}

\section{The citizenship category in the geography BNCC: the formative purposes in the burgish recomposition process}

\author{
Rodrigo Coutinho Andrade \\ Professor do Departamento de Geografia do Instituto Multidisciplinar da UFRRJ \\ rodrigoandrade@ufrrj.br \\ Luiz Fellype Xavier Costa \\ Graduando do curso de Geografia do Instituto Multidisciplinar da UFRRJ \\ luizfxvier@gmail.com
}

Artigo enviado para publicação em 17/09/2019 e aceito em 03/12/2019

DOI: $10.12957 /$ tamoios.2019.45353

\begin{abstract}
Resumo
Após a análise das premissas teóricas, epistemológicas e ético-políticas da Base Nacional Comum Curricular (BNCC) e sua refração nas competências para a Geografia nos diferentes níveis de ensino da Educação Básica, assim como exame de parte dos estudos das áreas de educação e ensino de geografia, identificamos na definição e instrumentalização da categoria cidadania rotunda convergência às predileções para a formação do "homem de novo tipo". Partimos da premissa de que as menções à categoria, enquanto "exercício", se coadunam aos mesmos princípios da Pedagogia Flexível com a finalidade de contemplar as novas morfologias do trabalho no contexto de recomposição burguesa, almejando a consolidação dos mecanismos de conformação da classe trabalhadora às transformações do/no mundo do trabalho, inexorável dos derivados para a reprodução social e material da/na ordem societária burguesa. Neste sentido, tomamos como objetivo o exame crítico das definições e usos da categoria em voga na BNCC e sua refração nas competências para a relação ensino-aprendizagem em Geografia. Trata-se de uma pesquisa básica, de análise qualitativa, de caráter explicativo, que se insere na categoria de pesquisa bibliográfico-documental.
\end{abstract}

Palavras-chave: Cidadania; Política Curricular; Ensino de Geografia; Formação Humana.

\section{Resumen}

Luego del análisis de las premisas teóricas, epistemológicas y ético-políticas de la Base Nacional Curricular Común (BNCC) y su refracción en las competencias de Geografía en los diferentes niveles de Educación Básica, así como el examen de parte de los estudios de las áreas de educación y enseñanza. de geografía, identificamos en la definición e instrumentalización de la categoría ciudadanía la convergencia indirecta a las predilecciones por la formación del "hombre del nuevo tipo". Partimos de la premisa de que las menciones de la categoría, como "ejercicio", están en línea con los mismos principios de la pedagogía flexible para contemplar las nuevas morfologías del trabajo en el contexto de la recomposición burguesa, con el objetivo de consolidar los mecanismos de conformación de la clase trabajadora para transformaciones inexorables de / en el mundo del trabajo de los derivados para la reproducción social y material 
de / en el orden social burgués. En este sentido, tenemos como objetivo el examen crítico de las definiciones y usos de la categoría en boga en BNCC y su refracción en las competencias para la relación enseñanza-aprendizaje en Geografía. Se trata de una investigación básica, análisis cualitativo, explicativo, que entra en la categoría de investigación bibliográfica-documental.

Palabras claves: Ciudadanía; Política curricular; Enseñanza de geografía; Formación humana.

\begin{abstract}
After the analysis of the theoretical, epistemological and ethical-political premises of the Common National Curriculum Base (BNCC) and its refraction in the competences for Geography in the different levels of Basic Education, as well as examination of part of the studies of the areas of education and teaching. of geography, we identified in the definition and instrumentalization of the category citizenship roundabout convergence to the predilections for the formation of the "man of the new type". We start from the premise that the mentions of the category, as "exercise", are in line with the same principles of Flexible Pedagogy in order to contemplate the new morphologies of work in the context of bourgeois recomposition, aiming at the consolidation of the working class conformation mechanisms to inexorable transformations of / in the world of work of the derivatives for the social and material reproduction of / in the bourgeois societal order. In this sense, we have as objective the critical examination of the definitions and uses of the category in vogue at BNCC and its refraction in the competences for the teaching-learning relationship in Geography. This is a basic research, qualitative analysis, explanatory, which falls into the category of bibliographic-documentary research.
\end{abstract}

Keywords: Citizenship; Curriculum Policy; Geography teaching; Human formation. 


\section{Introdução}

Após a análise da Base Nacional Comum Curricular (BNCC), da revisão bibliográfica parcial nas áreas de Educação e ensino de Geografia com foco nos estudos críticos sobre a formação humana sob a ótica do capital ${ }^{1}$, assim como o exame das políticas curriculares e seus impactos para a relação ensino-aprendizagem em Geografia na Educação Básica, concebemos o protagonismo da categoria cidadania e suas respectivas derivações para a (re)estruturação das finalidades formativas nos níveis de ensino Fundamental ${ }^{2}$ e Médio. Entre as diversas menções em todo o corpo do documento cabe destaque para sua adjetivação enquanto ação-exercício, tendo em sua capilaridade os princípios basilares para a consolidação de/dos valores éticopolíticos hegemônicos no atual contexto sócio-histórico. Neste sentido partimos da premissa no presente artigo, diante do escopo teórico-metodológico adotado, que o "manuseio" da categoria em questão advém das intencionalidades ético-políticas do bloco histórico (PORTELLI, 1978; GRAMSCI, 2015) para a formação do homem de novo tipo (GRAMSCI, 2015) no contexto de recomposição burguesa derivada da crise orgânica do capital ${ }^{3}$, forjando a nova engenharia para a sustentação das bases - corroídas - do regime de acumulação inexorável das predileções para sua reprodução sociometabólica (MÉSZÁROS, 2011) nos mesmo moldes da escola interessada (GRAMSCI, 2001).

O esgarçamento estrutural do capital pode ser conferido tanto no que tange à organicidade da totalidade sistêmica pelo continuum depressivo nos âmbitos da produção e das finanças em suas múltiplas dimensões, quanto em suas faces fenomênicas para a reprodução social e material da classe trabalhadora em decorrência da intensificação da precariedade e da ampliação da mercadorização da mão-de-obra (MÉSZÁROS, 2011; 2011a), tendo como epicentro a combinação entre a queda da taxa de lucro da burguesia, o subconsumopauperização das massas, a insustentabilidade ambiental e laboral, e os próprios "mecanismos de administração das crises" (ANTUNES, 2011), ou os meios de deslocamento desta (MÉSZÁROS, 2011) deflagrada pela recorrência conjuntural cada vez mais efêmera que denuncia o esgotamento deste modelo político-econômico - evidente nas sucessivas recessões após a década de 1970. Soma-se a isso o estágio atual de subsunção do precariado (BRAGA, 2015) às transformações do mundo do trabalho por meio das medidas de uberização, voucherização e intermitência do labor (ANTUNES, 2018), podendo ser mensurado nos dias atual pela elevação da informalidade no segmento demográfico jovem contabilizado em $89 \%$ pelo Programa Nacional por Amostras de Domicílios do Instituto Brasileiro de Geografia e Estatística (PNAD-IBGE) ${ }^{4}$, assim como na massa de desempregados estimada em $12,4 \%$ da População Economicamente Ativa (PEA), na totalidade de 12,8 milhões de sujeitos históricos no segundo trimestre de 2019 (IBGE, 2019), nos desalentados em 4,4\% e em aproximadamente $25 \%$ da força de trabalho subutilizada.

Sob este panorama objetivamos identificar a redefinição das finalidades formativas coadunadas às intencionalidades hegemônicas, verificando a incidência e a definição da categoria cidadania no corpo introdutório do documento e na organização das competências para a disciplina geográfica na área de Ciências Humanas, almejando a análise dos impactos da categoria em voga para a relação ensino-aprendizagem em Geografia como resultante da "nova geografia dos professores" (ROCHA, 2010). Em outras palavras, iremos analisar como a categoria cidadania refrata os princípios formativos da pedagogia política do capital no contexto de ofensiva neoliberal para a formação da classe trabalhadora, por meio do exame bibliográficodocumental, considerando as transformações da materialidade concreta no processo de reordenamento das morfologias do trabalho e das relações sociais de produção (ANTUNES, 2005; 2018). Ou seja, como se reifica a educação para o desemprego nas/sob as premissas da ideologia da empregabilidade. 
Antes de adentrar ao exame da categoria central da pesquisa na BNCC, para posteriormente expor as possíveis críticas nas áreas de estudo mencionadas, é salutar apontar três ressalvas. A primeira tange à impossibilidade assertiva da reprodução mimética do currículo nas práticas pedagógico-curriculares tanto em relação à empiria - o que requer examinar o cotidiano das diferentes unidades escolares no país -, quanto na recusa da crença do/no total consentimento ativo-passivo dos docentes de Geografia em seu labor ao projeto hegemônico. Ao mesmo tempo é plausível apontar que progressivamente se cristalizam medidas para a regulação dos professores na totalidade dos sistemas de ensino, o que nos leva a inferir novos ingredientes que confrontam sua autonomia, identidade e profissionalização por meio da combinação-articulação entre a ofensiva neoconservadora ${ }^{5}$ e o refino dos mecanismos de accountability educacional $^{6}$.

A segunda ressalva advém da historicidade das políticas curriculares acerca da tradição seletiva (SOUSA NETO, 1999), resultante da simbiose entre os determinantes hegemônicos e os derivados paradigmáticos para a organização dos conteúdos, ou das competências na contemporaneidade e sua estruturação epistêmica. No caso da ciência geográfica na escola, ou a Geografia escolar, isto pode ser conferido através das suas mutações ao longo do processo histórico, que em grande medida se espraiou no cotidiano didático-pedagógico por meio dos projetos societários, políticos e econômicos do bloco no poder (POULANTZAS, 1978), constituindo-se na própria Geografia dos Professores (LACOSTE, 1989) com impactos na formação docente neste campo científico.

A terceira consideração se remete ao contexto sócio-histórico em que se implementa a BNCC, compreendida aqui no bojo das ações contrarreformistas para a educação não dissociadas do recrudescimento da agenda neoliberal ortodoxa; vide a reforma do Ensino do Médio, a reestruturação da formação de professores tendo em vista a instrumentalização da BNCC para este campo, a reclusão do financiamento para todos os níveis e modalidades de ensino justificada pelo "ajuste fiscal”, etc. Em outras palavras, compreendemos a atual política curricular como um produto para a cristalização da política do conhecimento gerida-forjada pelas teses da Sociedade de Mont Pèlerin ${ }^{7}$. O receituário deste bloco, que se materializou no epicentro do capitalismo dentre os anos de 1970 e 1980, carrega em sua essência a desregulamentação da relação capital-trabalho e a revisão das finalidades público-estatais do Welfare State, impetrando uma série de medidas de flexibilização-privatização sob a égide financeira no processo de mundialização do capital (CHESNAIS, 1996; CASTELO, 2013; ANDERSON, 1995), logrando ao ostracismo os ditames do Estado de Bem-Estar Social. No entanto, ante a crise na década de 1980, com maior impacto sobre os países periféricos, ascende a mediação da terceira via nos ao longo das décadas posteriores, sendo rechaçada na atual concepção programática em que se institui a ortodoxia de face conservadora.

Entretanto, o que queremos apontar deste processo em relação aos determinantes para a formação humana se encontra nas novas demandas estruturais e superestruturais para a totalidade dos sistemas de ensino. Acerca da estrutura, como observamos até os dias atuais por meio da cristalização das novas morfologias do trabalho, se impetram uma série de medidas que impactam de sobremaneira as relações sociais de produção. Dentre tais destacamos a liofilização do/no chão de fábrica, a flexibilização do trabalho, a atomização-fragmentação no labor, o processo de terceirização-terciarização, a uberizaçao ${ }^{8}$ e as medidas de voucherização e zero hour contract (ANTUNES, 2005; 2011; 2018), tendo como epicentro a cooptação dos sujeitos sociais através da captura de/da sua subjetividade (ALVES, 2011) objetivando sua maleabilidade-adaptabilidade às novas transformações do mundo do trabalho, indissociável da ampliação da subsunção da classe trabalhadora em sua relação com a burguesia resultante do processo de composição orgânica do capital ${ }^{9}$. Soma-se a isto, ainda acerca do refino metódico da gestão do trabalho, a sobreposição das metas de produtividade que funde, nos dias atuais, a 
intensificação da imbricação do tempo do trabalho no tempo da vida em sua totalidade, destoando a imanência da regulação cronológica do trabalhador no contexto passado.

Acrescemos a tais assertivas, acerca das novas formas de trabalho $^{10}$ na contemporaneidade, a centralidade da/na adequação psicofísica do trabalhador às demandas do capital, o que fez ascender novas categorizações ${ }^{11}$ principalmente sobre a população jovem e feminina. Estes setores demográfico-sociológicos adentraram em um período de "recusa" ao trabalho no que tange à valoração fordista resultante da ofensiva ideológica do labor como forma de subsistência, criando uma população instável sem qualquer reivindicação jurídica sobre as condições oferecidas (LINHART, 2007, p. 37).

\begin{abstract}
O aumento de empregos precários, sobretudo dos jovens e das mulheres, é antes de mais nada o resultado de uma estratégia patronal que visa à maior flexibilidade possível na gestão da mão-de-obra, transformada em uma questão crucial em períodos de "crise" econômica. Mas podemos pensar que o crescimento das formas precárias de emprego (provisório, contratos por tempo determinados, estágios, tempo parcial), que tornam caduca uma parte da proteção social dos trabalhadores, encontrou apoio no "ambiente ideológico" criado por todos esses discursos e análise sobre a emergência de uma nova relação com o trabalho. Se, de fato, considerarmos que a maior parte dos jovens tem somente uma relação instrumental com o trabalho, ou seja, que o vê apenas como um simples meio de ganhar a vida, e que, portanto, sua socialização se faz em outros lugares, não há mais motivo para se chocar com a ampliação desses empregos temporários no mercado de trabalho (LINHART, 2007, p. 38).
\end{abstract}

Não se modifica a relação capital-trabalho somente por meio da ascensão das novas formas de ocupação, mas a própria relação com trabalho e o seu desempenho na vida das pessoas. O mesmo, que outrora poderia ser concebido como espaço das reproduções sociais, o que não deixa de ser atualmente, se altera cada vez mais no sentido de sua negação. O trabalho deixa de ordenar o tempo, se desideologiza, desestruturando também a esfera fora do trabalho, sendo o próprio sentido de envolvimento uma estratégia de captura da empresa toyotista para a construção do pertencimento a algo efêmero e mutável a qualquer instante.

A conclusão que chegamos sobre as mutações do trabalho, no contexto da reestruturação produtiva, é a de que a ofensiva do capital tem como característica estruturante-endêmica o avanço e a aniquilação da própria identidade dos trabalhadores na conjuntura de flexibilização da mão-de-obra, de acentuação do desemprego estrutural e da redefinição dos valores existenciais (SENNETT, 2012, p. 63). A contradição que permeia o processo de enxugamento empresarial, assim como a especialização flexível do trabalhador e as demais formas de ocupação, está arraigada de estratégias para sua desqualificação e desorganização como os novos componentes ideológicos da gestão do trabalho, dos Círculos de Controle de Qualidade (CCQs), da qualidade total e principalmente da gestão participativa, que cria organicamente um novo tipo de trabalhador denominado agora como "colaborador", "empreendedor", "voluntário", etc.

Neste sentido, podemos reiterar que as transformações do paradigma flexível cristalizaram efeitos rotundos para a intensificação da precariedade dos trabalhadores decorrente da ascensão progressiva do desemprego estrutural, ascendendo o trabalho atípico, as novas formas de reprodução material deslocados cada vez mais para a responsabilização dos sujeitos sociais - incorporados progressivamente no setor informal -, e a retração do sindicalismo reativo e das formas-essências históricas da luta da classe trabalhadora refletida tanto no processo de dessindicalização, quanto nas novas grafias de contratação e instabilidade provocadas pela magnitude do exército industrial de reserva - requerendo sincronicamente um exército industrial de reserva de novo tipo. Isto trouxe novos elementos para a Educação Básica, estruturados principalmente na/pela Pedagogia das Competências, na individualização da 
relação ensino-aprendizagem e no incremento explícito-oculto da responsabilização - ainda na Educação Infantil de modo atomizado-competitivo - dos indivíduos sobre sua subsistência através da ideologia da empregabilidade e do recrudescimento da Teoria do Capital Humano.

Os mecanismos para a efetivação dos anseios estruturais ocorreram no âmbito superestrutural no país após a Reforma Gerencial do Estado no primeiro governo Fernando Henrique Cardoso (1995-1998), imputando medidas acordadas às teses do gerencialismo e da Nova Gestão Pública (NGP) para a ampliação da "eficácia-eficiência" da "máquina pública" e do controle social na/da gestão das políticas públicas sob os princípios do mercado, desencadeando nas privatizações de diversas empresas estatais, na publicização da oferta dos serviços básicos por meio das parcerias com a sociedade civil e com o empresariado ${ }^{12}$, e nas medidas circunscritas à quantofrenia (GAULEJAC, 2007), tendo como principal legitimação a negação do Estado "burocrático-weberiano" mesmo com todos paradoxos da/sobre a real efetivação do Estado de Bem-Estar Social no Brasil. Em relação à educação observamos que os desdobramentos da ofensiva neoliberal, mediada pela Terceira Via, imputaram transformações em todos os campos após esse processo, cabendo destaque para a Lei de Diretrizes e Bases da Educação Brasileira (LDB), para as políticas de financiamento após a implementação do Fundo de Manutenção e Desenvolvimento do Ensino Fundamental e de Valorização do Magistério (FUNDEF) e do Fundo de Manutenção e Desenvolvimento da Educação Básica e de Valorização dos Profissionais da Educação (FUNDEB), para as políticas curriculares com a criação dos Parâmetros Curriculares Nacionais (PCN) e a BNCC nos dias atuais, inexorável das Diretrizes Curriculares Nacionais (DCN), para a formação de professores e nas medidas de responsabilização docente com a criação dos indicadores de desempenho ${ }^{13}$, e a última ênfase para as avaliações externas em todos os níveis de ensino ${ }^{14}$.

No âmbito político derivado deste processo, como explícito na BNCC e nos documentos dos organismos internacionais para a educação, se observa um conjunto de transformações para a formação do "cidadão de novo tipo", tendo como centralidade as ações na escala local de modo individualizado sob os princípios da responsabilidade social por meio da apologia ao desenvolvimento sustentável e as demais iniciativas do voluntarismo e comunitarismo. Reiteramos que isto se reflete na reformulação das prescrições curriculares de modo indissociável das demandas estruturais, como veremos no documento tomado como objeto do presente estudo.

\section{Considerações acerca da categoria cidadania na BNCC}

O termo cidadania se tornou, hoje, uma espécie de lugar-comum. E ele também foi incorporado pelo discurso pedagógico, inclusive o de esquerda. É comum ouvir-se falar, por estes autores, em educação cidadã, educar para a cidadania, formar cidadãos críticos. Embora haja diferenças entre os diversos autores acerca do conteúdo deste termo, pode-se dizer que, de modo geral, ele é tomado como sinônimo de liberdade. Vale dizer, contribuir para a formação de cidadãos seria contribuir para a formação sempre processual - de indivíduos cada vez mais livres e humanos (TONET, 2005, p. 470).

Antes de adentrarmos à análise da categoria cidadania na BNCC podemos afirmar, ante o exame bibliográfico, que esta é utilizada de sobremaneira nos estudos e pesquisas da área de Ensino de Geografia como uma finalidade ideal-material. Ao mesmo tempo em que corroboramos com as vicissitudes - paradoxais até - de seus usos, sentimos imenso deslocamento deste debate com as peculiaridades da materialidade concreta no qual a vida, na escala do lugar também, se efetiva. Cientes das peculiaridades do cotidiano e sua plena heterogeneidade-simultaneidade, buscamos ancorar o presente artigo na análise sobre o elemento ontológico humano - trabalho - e sua aparências na contemporaneidade, que podem ser conferidas no dia-a-dia da metrópole através dos ocupados em bicicletas alugadas que 
circulam para entrega de alimentos, ou outros produtos ${ }^{15}$, com pífios rendimentos - muitas vezes aquém do salário mínimo, entendido não como o necessário para a subsistência, mas o valor estipulado para a subsistência em dialética combinação à mais valia -, ou no isolamento completo da burguesia cada vez mais mediada pelos softwares implicando tanto na ampliação da mais-valia relativa e absoluta.

Neste sentido, considerar sobre a cidadania na contemporaneidade requer, sob nossa visão, minimamente compreender a forma no qual ela se institui nos discursos e se reifica no senso comum, que obsta as mediações-contradições que imbuem o discurso. Com isso reiteramos inicialmente que esta sintetiza em diferentes flancos os anseios da sociabilidade burguesa pelos princípios da liberdade individual, se transmutando para o espaço escolar por meio da responsabilização da reprodução material-intelectual calcada nos indivíduos composta pelo estratagema de sua restrição à dimensão política, eximindo em grande magnitude a base material da sociabilidade e as contradições estruturais (TONET, 2007, p. 471) nos mesmo moldes da auto-incriminação do Estado (BORÓN, 1995), da despolitização da política (SIMIONATTO, 2004) ou do deslocamento da estrutura (WOOD, 2014).

A teoria liberal da cidadania (Kant, Hobbes, Locke, Rousseau e outros) tem como pressuposto que todos os homens são iguais e livres por natureza. As desigualdades sociais seriam apenas o desdobramento da igualdade e da liberdade naturais. A busca da realização pessoal, uma exigência da liberdade e da igualdade naturais, teria dado origem a toda sorte de conflitos que, na ausência de qualquer elemento inibidor, poderiam pôr em perigo a sobrevivência da própria humanidade. Por isso mesmo, os homens ter-se-iam visto obrigados a se organizar em sociedade e a instituir uma autoridade (Estado) capaz de garantir a observância de certos limites. Deste modo, a desigualdade social é considerada legítima e constitutiva do mundo humano. Tratavase, pois, não de suprimi-la, o que seria impossível, mas apenas de coibir os seus excessos.

Como se pode ver, ainda que não se falasse em cidadania, a igualdade e a liberdade naturais já punham a base para o seu desenvolvimento futuro. Neste sentido, todos os homens já eram potencialmente cidadãos. O desenvolvimento posterior, sempre complexo e contraditório, seria apenas a concretização daquilo que já estava posto, como possibilidade, desde o início. Mas a cidadania seria sempre vista como um instrumento para equilibrar as desigualdades sociais e não para erradicá-las (TONET, 2005, p. 472).

Diante das premissas expostas acerca das intencionalidades do bloco histórico no contexto de recomposição burguesa para a formação humana, identificaremos a instrumentalização da categoria cidadania na prescrição curricular em diferentes momentos, articulando esta às finalidades formativas discriminadas para o exercício dialético da liberdade. Desde já corroboramos com a análise de Tonet (2005) sobre o tema e a sua conclusão do "lugarcomum" que o termo-categoria cidadania se tornou nos dias atuais, espraiando por meio dos aparelhos privados de hegemonia os anseios éticos, morais e políticos da democracia liberal burguesa - com teleologias para a mediação do conflito de classes (SOUZA, 2002). Mergulhando no texto da BNNC, identificamos que a sua primeira menção ocorre na introdução do documento articulada à definição de competência.

Na BNCC, competência é definida como a mobilização de conhecimentos (conceitos e procedimentos), habilidades (práticas, cognitivas e socioemocionais), atitudes e valores para resolver demandas complexas da vida cotidiana, do pleno exercício da cidadania e do mundo do trabalho (BRASIL, 2018, p. 8).

Compreendemos que a terminologia competência, incorporada nos documentos oficiais para a educação a partir da década de 1990 em concomitância aos derivados dos organismos internacionais, está intrinsecamente radicada nos determinantes estruturais, de acordo com os 
estudos da Sociologia do Trabalho e da área de educação, em decorrência da nova base técnica implementada pelo regime de acumulação flexível calcada na reconfiguração dos modelos das competências profissionais que se configura no "terreno ideológico a partir do qual se disseminam as noções estruturantes de flexibilidade, transferibilidade, polivalência e empregabilidade que irão determinar o uso, controle, formação e avaliação do desempenho da força de trabalho" (ALVES, 2011, p. 76).

Nos dias atuais podemos conceber a competência individual indissociável da noção de empregabilidade e do saber fazer (BRASIL, 2018, p. 13) nos moldes da liberdade societária liberal-burguesa, que abrange de todo modo a totalidade da vida cotidiana compreendida como exercício da cidadania impetrados pelas relações sociais de produção na contemporaneidade. Por meio das competências e da sua Pedagogia, no contexto da crise do emprego, se desloca o conceito de qualificação ${ }^{16}$ sustentada como posto fixo no trabalho, ou comprovada mediante o diploma, para a competência - sendo esta transposta para o cotidiano como projeto civilizatório.

Por essa ótica, a emergência da noção de competência é fortemente associada a novas concepções do trabalho baseadas na flexibilidade e na reconversão permanente, em que se inscrevem atributos como autonomia, responsabilidade, capacidade de comunicação e polivalência. Neste sentido, o domínio do processo de trabalho faz apelo às qualificações tácitas, implícitas e não formalizadas por parte dos trabalhadores (RAMOS, 2001, p. 66).

A assertiva é ainda mais contundente quando analisamos os princípios formativos para o Ensino Médio, que tem como pilar:

Proporcionar uma cultura favorável ao desenvolvimento de atitudes, capacidades e valores que promovam o empreendedorismo (criatividade, inovação, organização, planejamento, responsabilidade, liderança, colaboração, visão de futuro, assunção de riscos, resiliência e curiosidade científica, entre outros), entendido como competência essencial ao desenvolvimento pessoal, à cidadania ativa, à inclusão social e à empregabilidade (BRASIL, 2018, p. 466).

Soma-se a isto as prerrogativas da epistemologia hegemônica para a relação ensinoaprendizagem sob as premissas flexibilização e da pós-modernidade, que ganharam mais fôlego após a reforma do Ensino Médio. Acerca da primeira podemos ressaltar, em convergência ao estudo de Kuenzer (2017), que a aprendizagem flexível, no qual se sustenta a própria categoria em análise aqui, se coloca de modo simétrico à própria compreensão do currículo na contemporaneidade sob a ótica do capital, que progressivamente aporta por meio dos discursos oficiais, assim como dos intelectuais orgânicos do capital, como ente necessário para a superação da metanarrativa unívoca das trajetórias, do conteudismo-disciplinarização, da liberdade de escolha, e do protagonismo do professor ante à autonomia dos estudantes. Por meio da defesa da "emancipação" estudantil para a organização da sua própria aprendizagem, autonomia e comprometimento que, em tese, superaria o individualismo, se reifica o conteúdo do Relatório Delors (UNESCO, 1996) para a materialização dos princípios do "aprender a aprender". Sob outra ótica, a flexibilidade é concebida material e subjetivamente almejando a polivalência no/do labor no contexto de refino da dualidade escolar, das novas morfologias do trabalho e das vicissitudes atuais da fragmentação entre o trabalho simples e complexo, pois as necessidades de produção são cada vez mais ditadas pelo labor em si, descartando a formação nos moldes ford-tayloristas. Além disso,

[...] Essa concepção metodológica desloca não só o professor, mas também o conteúdo para o grupo, mediante a organização de comunidades de aprendizagem, em que os alunos participam, envolvem-se, pesquisam, interagem, criam, com a mediação de algum orientador. $\mathrm{O}$ professor passa a ser organizador de conteúdos e produtor de 
propostas de curso, de abordagens inovadoras de aprendizagem, em parceria com especialistas em tecnologia; a relação presencial passa a ser substituída pela tutoria, que acompanha a aprendizagem dos alunos (KUENZER, 2017, p. 338).

Continuando o exame da pedagogia flexível, a autora supracitada reitera que a mesma reproduz em sua sintaxe a superação da práxis para a consolidação da prática respaldado pelo "aprender a fazer", incentivada no último nível de ensino da Educação Básica por meio dos itinerários formativos e da flexibilização curricular - algo próximo do modelo norte-americano (RAVITCH, 2011). O conhecimento, e sua política na contemporaneidade impactando também a formação docente, se consolidaria pela abrupta crítica ao academicismo, ou pelo pleno domínio da teoria, que facilitaria também a mediação do processo de aprendizagem em meios virtuais e em cursos à distância onde

[...] São apresentadas leituras selecionadas pelo conteudista, que serão interpretadas em exercícios previamente propostos, que geralmente não atingem os níveis mais complexos dos comportamentos cognitivos, atendo-se, na maioria das vezes, à reprodução de conhecimentos já construídos para o reconhecimento de fatos ou situações comuns, por operações mentais tais como descrição, identificação, indicação; ou ao estabelecimento de relações que permitem tecer explicações para os fenômenos observados. São pouco frequentes os exercícios que demandam operações mentais mais complexas, como avaliar, criticar, criar soluções para situações inéditas, solucionar casos complexos que ensejam múltiplas respostas, criticar resultados, fazer diagnósticos e assim por diante (KUENZER, 2017, p. 344).

Com base no fetiche da prática (SOUZA, 2018) o conhecimento passa a ser cada vez mais superficializado objetivando a resolução de situações-problema por meio da reflexão da prática meramente, cada vez menos intercalada à teoria, provocando a nova face instrumental da escola para o trabalho simples. Isto se coaduna às premissas pós-modernas para a educação no que tange à negação dos princípios da totalidade, quando a abordagem da categoria cidadania se interage-limita às narrativas do cotidiano, do presentismo e do pragmatismo (KUENZER, 2017). Passa-se para a recusa da práxis e da historicidade para a sobrevalorização do presente. Supera-se a construção histórica do conhecimento pelas narrativas. "A experiência histórica é substituída pela experiência do momento; as organizações históricas e suas experiências acumuladas são substituídas pelo ativismo" (KUENZER, 2017, p. 347), no qual se sobrepõe sobre o coletivo-classe a referenciação da vida pelo "ineditismo", imediatismo e das posições políticas atomicistas de cunho voluntário principalmente, sendo capturado também pelo paradigma da responsabilidade social empresarial (CESAR, 2008). Seria esta uma racionalidade que destraça o universalismo agora situados distantes, ou o conteudismoabstração pura, reforçando "o individualismo, reduzindo-se a sociedade à interação entre indivíduos e as relações sociais ao plano individual (escolhas pessoais)" (KUENZER, 2017, p. 348).

\footnotetext{
Consequentemente, não há teorias sociais, pois elas são ilusões que disfarçam interesses particulares; a totalidade passa a ser um recurso metodológico impossível, pois não há como estabelecer relações causais entre fenômenos sociais. A totalidade é substituída pela fragmentação e as disciplinas que podem fornecer elementos para a crítica e consequente apreensão das relações sociais concretas em seu caráter de totalidade, são relegadas a um lugar secundário na parte comum do currículo, ou a uma área que se basta em si mesma (KUENZER, 2017, p. 348).
}

A epistemologia da prática, ancorada nos princípios da Pedagogia das Competências, se corresponde de imediato ao pragmatismo permeado de modo visceral à verdade posta à utilidade aparente-imediata. Neste sentido, o conhecimento se transmuta para a abstraçãocognição advinda da prática, e teleologicamente potencializada para a transformação da 
realidade restrita na eficácia e na manipulação do prático para si pautado pela sensibilidadepercepção. A empiria se transforma no fim em si, não como partida, ou até mediação, abarcando tanto as escolhas - free choice - ao longo da formação, quanto nas ações "cidadãs" sem a mínima prescrição das causas em sua essência-totalidade - como o próprio princípio epistêmico sustenta $^{17}$.

No segundo momento o uso da categoria cidadania se espelha em prol da valorização da diversidade e da qualificação social ${ }^{18}$, assim como para a apropriação dos conhecimentos da dinâmica do mundo do trabalho e para "fazer escolhas alinhadas ao exercício da cidadania e ao seu projeto de vida, com liberdade, autonomia, consciência crítica e responsabilidade" (BRASIL, 2018, p. 9). Esta parte do texto nos coloca sobre a óbvia questão: o que seria realizar uma escolha alinhada ao exercício da cidadania, considerando o atual contexto sócio-histórico? A resposta nos encaminha no primeiro momento, de acordo com o arcabouço teóricometodológico do presente estudo, para a análise de Neves (2005) acerca da consolidação da Nova Pedagogia da Hegemonia. Isto por cristalizar - por meio dos aparelhos privados de hegemonia - no processo formativo a "nova" cultura cívica como ente para a reconfiguração dos mecanismos de mediação do conflito de classe.

\begin{abstract}
Essa educação vem sendo propagada por diferentes meios, mas a escola continua sendo o espaço privilegiado para a conformação ético-política do "novo homem", de acordo com os princípios hegemônicos. O "novo homem", nessa visão de mundo, deve: sentir-se responsável individualmente pela amenização de uma parte da miséria do planeta e pela preservação do meio ambiente; estar preparado para doar uma parcela do seu tempo livre para atividades voluntárias nessa direção; exigir do Estado em senso estrito transparência e comprometimento com as questões sociais, mas não deve jamais questionar a essência do capitalismo. À escola, portanto, é transmitida a tarefa de ensinar as futuras gerações a exercer uma cidadania de "qualidade nova", a partir do qual o espírito de competitividade seja desenvolvido em paralelo ao espírito de solidariedade, por intermédio do abandono da perspectiva de classe e da execução de tarefas de caráter tópico na amenização da miséria em nível local (NEVES, 2005, p. 211).
\end{abstract}

A cidadania de qualidade nova resulta do novo ordenamento social mundial que requer a revisão das condutas individuais, corporativas e dos governos (NEVES; MARTINS, 2015, p. 35) é resultante das teses da Sociedade do Conhecimento (DRUCKER, 1993), tomando como sustentação a noção de colaboração social na limitação da participação política por via das estratégias da "democracia consentida" (NEVES; MARTINS, 2015, p. 35). Sua materialização se intensificou ao longo dos anos 1990, no campo da educação, após a Conferência de Jomtien - que originou o programa Educação para Todos da UNESCO. Movimento que germinou o processo de expansão da escolarização sob o discurso neoliberal mediado pelas teses da Terceira Via, principalmente para a consolidação dos princípios da cidadania com foco nos direitos de aprendizagem, na responsabilidade social, no desenvolvimento sustentável e na geração de renda, tendo como vértice o expurgo existencial dos sujeitos históricos enquanto classe.

Seria esta a face do "capitalismo humanizado" que, por meio da construção do consenso sobre valores no bojo da dialética mercado-justiça social, promove a reconstrução do conteúdo pedagógico-curricular dos/nos sistemas de ensino. Através do discurso da crise da escola calcado em sua ineficiência para a obtenção dos resultados e para a garantia da coesão social, a classe empresarial passa a entrar na escola para difundir seu ideário de vida (NEVES; MARTINS, 2015) - vide as ações do Movimento Todos pela Educação e os sentidos da pulblicização da oferta pública de ensino associada ao empresariado nas diferentes redes. Estas reflexões se coadunam ao segundo vértice proposto para a instrumentalização da "cidadania de qualidade nova", onde a diversidade se simetriza às vicissitudes das re-existências na escala do lugar como ponto de heterogeneidade da verticalidade global, mas sendo captada por este 
processo. Transformando a cultura como um produto, cabendo as devidas ressalvas, se imputa sua massificação por meio da diferenciação que escamoteia o processo de sua apropriação enquanto ente existencial-mercadoria, como as iniciativas do respeito às diferenças no convívio dialético aos matáveis (AGAMBEN, 2015). A própria diferença-identidade se torna homogeneização-heterogeneização, mesmo que negado no discurso (KUENZER, 2007).

Por fim, inexorável do que expomos anteriormente, destacamos que a categoria cidadania refrata de modo repetitivo a combinação entre a fragmentação dos indivíduos enquanto "sujeitos", tendo como foco sua interação concreta limitada à escala do lugar, sendo a totalidade concebida pelos meios digitais e deslocada de seus impactos na materialidade concreta vivida-concebida pelos estudantes, complementar à vaga adjetivação da cidadania.

A compreensão dos estudantes como sujeitos com histórias e saberes construídos nas interações com outras pessoas, tanto do entorno social mais próximo quanto do universo da cultura midiática e digital, fortalece o potencial da escola como espaço formador e orientador para a cidadania consciente, crítica e participativa (BRASIL, 2018, p. 62).

Esta concepção sobre a (de)limitação das ações no cotidiano, presas à escala do lugar e, consecutivamente, isoladas da totalidade concreta, fica ainda mais explícita nas competências ético-políticas para o Ensino Médio.

É importante também que eles possam refletir sobre as possibilidades de utilização dos espaços públicos e privados que frequentam para desenvolvimento de práticas corporais, inclusive as aprendidas na escola, de modo a exercer sua cidadania e seu protagonismo comunitário (BRASIL, 2018, p. 484).

\title{
A categoria cidadania e o ensino de Geografia na BNCC
}

Em relação às Ciências Humanas no Ensino Médio, a instrumentalização da categoria em voga se destaca seguindo os princípios aqui já apontados por meio do incentivo à participação do debate público - sem mencionar do que se trata, vide a clausura consultiva nos dias atuais em todas as instâncias - de modo crítico, "respeitando diferentes posições e fazendo escolhas alinhadas ao exercício da cidadania e ao seu projeto de vida, com liberdade, autonomia, consciência crítica e responsabilidade" (BRASIL, 2018, p. 570), sendo melhor especificado na sexta competência desta área de conhecimento.

\begin{abstract}
A construção da cidadania é um exercício contínuo, dinâmico e que demanda a participação de todos para assegurar seus direitos e fazer cumprir deveres pactuados por princípios constitucionais e de respeito aos direitos humanos. Assim, para que os estudantes compreendam a importância de sua participação e sejam estimulados a atuar como cidadãos responsáveis e críticos, essa competência específica propõe que percebam o papel da política na vida pública, discutam a natureza e as funções do Estado e o papel de diferentes sujeitos e organismos no funcionamento social, e analisem experiências políticas à luz de conceitos políticos básicos. (BRASIL, 2018, p. 578).
\end{abstract}

Ao mesmo tempo em que se delimita à cidadania como exercício-prática no bojo dos direitos e deveres, como concebido repetitivamente no componente curricular História, se reitera a responsabilização dos estudantes no "terreno" da política na vida pública e nas limitações do Estado nos ditames da Constituição. Não se coloca as contradições para a baila, assim como se delimita à "participação cidadã" nos intercursos superestruturais, destoantes das bases do regime de acumulação - no qual se impetra a maleabilidade-adaptabilidade através da ideologia da empregabilidade. Em relação à instrumentalização da categoria em questão na BNCC para a Geografia na Educação Básica não encontramos elementos destoantes do que já 
fora apontado, mas sua imbricação com os entes paradigmáticos contemporâneos para a reprodução do conhecimento geográfico na escola, ancorados principalmente na construção de conceitos para a sustentação do "raciocínio geográfico".

Essa é a grande contribuição da Geografia aos alunos da Educação Básica: desenvolver o pensamento espacial, estimulando o raciocínio geográfico para representar e interpretar o mundo em permanente transformação e relacionando componentes da sociedade e da natureza. Para tanto, é necessário assegurar a apropriação de conceitos para o domínio do conhecimento fatual (com destaque para os acontecimentos que podem ser observados e localizados no tempo e no espaço) e para o exercício da cidadania (BRASIL, 2018, p. 365).

A não diferenciação da totalidade do texto se exprime na finalidade do ensino de Geografia no Ensino Fundamental, que reitera a cidadania enquanto exercício indissociável da vida cotidiana e do lugar, tendo como finalidade as intencionalidades da "cidadania do novo tipo" no âmago da convivência e o bem comum.

Em todas essas unidades, destacam-se aspectos relacionados ao exercício da cidadania e à aplicação de conhecimentos da Geografia diante de situações e problemas da vida cotidiana, tais como: estabelecer regras de convivência na escola e na comunidade; discutir propostas de ampliação de espaços públicos; e propor ações de intervenção na realidade, tudo visando à melhoria da coletividade e do bem comum (BRASIL, 2018, p. 363 - grifo nosso).

Tais finalidades correspondem às premissas apontadas, assim como as derivações contemporâneas da categoria cidadania e sua instrumentalização para o "conhecimento factual" observado, assegurando os conceitos como mediação na escala-rotina cotidiano. Ao mesmo tempo, além de constituir no sujeito-indivíduo as consignas para sua reprodução social e material no contexto de crise orgânica do capital, destituindo os determinantes do bloco histórico das causalidades, não aprofunda em nenhum momento os significados do "bem comum", deixando de modo implícito a reprodução dos ditames da sociabilidade contemporânea - burguesa. Isto se aprofunda quando verificamos a reprodução das suas intencionalidades no Ensino Médio considerando a especificidade etária.

Para atender às necessidades de formação geral, indispensáveis ao exercício da cidadania e à inserção no mundo do trabalho, e responder à diversidade de expectativas dos jovens quanto à sua formação, a escola que acolhe as juventudes tem de estar comprometida com a educação integral dos estudantes e com a construção de seu projeto de vida (BRASIL, 2018, p. 464 - grifo nosso).

Acerca da estruturação da Geografia na BNCC em relação ao arcabouço teóricometodológico, assim como a organização das competências, observamos um certo ecletismo como já apontado por Rocha (2010) em sua análise dos PCN. Para a consolidação de sua finalidade enquanto componente curricular se mescla os diferentes conceitos geográficos, para a "construção da identidade", aos derivados epistêmicos do espaço vivido com base nos pressupostos da fenomenologia e do socioconstrutivismo para a reprodução das vicissitudes do raciocínio geográfico, calcados na diferença e na identidade (MOREIRA, 1999) reificado enquanto Geografia Oficial (ROCHA, 2010, p. 23). No entanto o último - raciocínio geográfico -, tomado como principal fundamentação para a ciência geográfica na escola, se espraia no método da "Geografia Tradicional" (BRASIL, 2018, p. 361), o que deixa claro a insuficiência metódica do paradigma fenomenológico na/para a geografia escolar, que se agrava ao capturar a análise de Moreira (1999, pp. 41-53) sem considerar seu conteúdo marxista para o desvelo da reafirmação da diferença, do espaço. 
Se no passado o PCN de Geografia se exercitou para lograr ao ostracismo as contribuições do marxismo através de argumentações simplórias (ROCHA, 1999), nesta prescrição curricular ocorre de modo sincrético mantendo a mesma premissa e até, com as ressalvas do termo, oportunista, pois não vislumbra em momento nenhum a identidade por meio da "diferença como conteúdo concreto. Não diferença como mediação da identidade, pura categoria do método da representação" (MOREIRA, 1999, p. 54), mas a diferença que polimorfiza o sujeito imputando a "morte do sujeito universal", do sujeito como classe, como também frisa Rocha (2010, p. 24).

\section{Considerações finais}

Considerando as limitações de um artigo científico apontamos, mesmo que de modo panorâmico, as bases sócio-históricas para a reprodução do conhecimento escolar na contemporaneidade tomando as mutações impetradas pelo processo de recomposição burguesa. Esta alcança a totalidade dos sistemas de ensino tanto na gestão das políticas educacionais, quanto nas verticalidades para a relação ensino-aprendizagem. Sobre o último identificamos, por meio da categoria cidadania, os ancoradouros para a formação do "homem de novo tipo" através da cimentação da Pedagogia das Competências e de toda reformulação das políticas curriculares sob as premissas da Pedagogia da Hegemonia, que tem como finalidade a construção de mecanismos para a mediação do conflito de classes e a obtenção da maleabilidade dos futuros trabalhadores às novas morfologias do trabalho.

Doravante, reconhecendo as vicissitudes do empreendimento educacional aparelhado à agenda neoliberal internacional, compreendemos conveniente delimitar, ainda que brevemente, as diferenças ontológicas referentes à emancipação humana e emancipação política. Isto posto, em alicerce às concepções teóricas de Ivo Tonet (2005), a emancipação política consiste inexoravelmente na instrumentalização da cidadania - enquanto ação-exercício - advindas de intencionalidades ético-políticas para a sustentação da sociabilidade fundada na reprodução capitalista requerendo a limitação da liberdade do indivíduo pelas prescrições do capital. Em contraposto, a edificação da emancipação humana advém da autoconstrução do ser social estruturado na liberdade plena e ilimitada gerada por uma atividade educativa que pressuponha a construção de indivíduos livres, outrossim, a cidadania coadunada à emancipação humana deve romper com a lógica do capital e ser reproduzida no bojo da vida social (TONET, 2005).

Para a identificação da nova reengenharia no bojo da tradição seletiva, expomos as premissas da BNCC para a formação humana e suas refrações para a Geografia enquanto componente curricular. Diante do examinado, concluímos que o paradigma hegemônico hoje no campo de ensino de Geografia, devendo ser ressaltado suas relevantes contribuições para o avanço desta ciência no espaço escolar, se imbrica de modo fortuito para a contemplação das finalidades formativas sob a ótica do capital, contendo em seu vértice os elementos epistemológicos das mediações da Terceira Via em seus objetivos e finalidades. Ademais, isto se reitera pela individualização do processo (ensino)aprendizagem, assim como sua predisposição para o subjetivismo amparado no conceito de espaço vivido, se conflagrando progressivamente enquanto a Geografia oficial consentida ao projeto hegemônico.

Ao mesmo tempo em que concebemos contribuições teóricas para a construção dos conhecimentos geográficos para a compreensão e transformação do mundo ancorados na relevância dos conceitos, podemos afirmar que a BNCC se institui como pressuposto discursivo para a prática deslocada da reflexão - Pedagogia Flexível (KUENZER, 2007) - apontando a sincronia entre a manutenção do ordenamento conteudístico nas mesmas premissas dos PCN, que reflete de sobremaneira os princípios dos organismos internacionais sob os ditames do "aprender a aprender" e do "aprender a fazer", indissociável da organização dos conteúdos sob os moldes da ação na escala local, e reduzida por esta, aniquilando a potencialidade metódica- 
metodológica da totalidade, (con)fundindo o conhecimento significativo ao útil - o último predeterminado para as demandas estruturais em sua pragmaticidade e instrumentalidade - nos moldes retóricos dos formuladores do currículo (YOUNG, 2011).

Portanto, corroboramos com a crítica de Couto (2016) ao evidenciar o currículo - BNCC - e sua concepção por meio das premissas da regulação-avaliação (AFONSO, 2000) centrado nos objetivos-direitos de aprendizagem que suprime, em movimentos sincrônicos, a diversificação e a própria centralidade do conhecimento pautado na instrução e no sentido da escola para a reprodução do conhecimento historicamente produzido-acumulado-sistematizado. Couto (2016, p. 191) bem observa que o cotidiano-experiência, no escopo dos objetivos de aprendizagem como prisma central, e a geografia sob este epiteto, reduz "o papel da escola à instituição de regulação do comportamento individual através de vivências e atividades sobretudo de caráter cultural, visando a manutenção da coesão social no contexto cruel, conflituoso e desigual da sociedade brasileira", refratado também na própria conceptualização das Ciências Humanas.

\section{Notas}

1 - Segundo Souza (2002, p. 17), a ótica do capital identifica o caráter formativo hegemônico da classe trabalhadora, diante das "concepções e propostas vinculadas à utilização da força de trabalho para a produção da mais-valia", reiterando a fragmentação entre a teoria e a prática, impondo limites claros a educação da classe trabalhadora, através do desigual acesso ao conhecimento científico e tecnológico.

2 - Consideraremos nesta pesquisa apenas os anos finais do Ensino Fundamental.

3 - A categoria recomposição burguesa consiste na peculiaridade histórica de tal classe, no sistema capitalista, "de revolucionar incessantemente os instrumentos de produção, por conseguinte, as relações de produção e, com isso, todas as relações sociais" (MARX; ENGELS, 2015, p. 12).

4 - Ver: https://www.valor.com.br/brasil/6412161/89-dos-novos-empregos-dos-jovens-sao-informais?fbclid=IwA R2ID5z1n wLDm-mky9qe9qxyarApBIOjdmuuAVqKAC-ci2k4Se13jacLEfg.

5 - Esta pressupõe a reorientação do currículo oculto e prescrito por meio dos valores liberais e conservadores, indissociável do cerceamento crítico dos docentes, tendo como principal representante na sociedade civil o Movimento Escola sem Partido.

6 - São estratégias calcadas nos pressupostos do gerencialismo que, sob a verve ideológica neoliberal acerca da qualidade da educação, impetra mecanismos de aferição dos resultados e regulação da atividade docente - como as avaliações externas e indicadores de desemprenho. Portanto, ao mesmo tempo em que legitima os estratagemas meritocráticos inexoráveis da responsabilização dos/por resultados, consolida teoricamente a reprodução das prescrições curriculares por meio da aferição do conhecimento escolar (AFONSO, 2000; SCHNEIDER; NARDI, 2014).

7 - Esta seria "uma espécie de franco-maçonaria neoliberal, altamente dedicada e organizada, com reuniões internacionais a cada dois anos. Seu propósito era combater o keynesianismo e o solidarismo reinantes e preparar as bases de um outro tipo de capitalismo, duro e livre das regras para o futuro" (ANDERSON, 1995, p. 10). Sua gênese pode ser demarcada após a publicação da primeira edição do livro $O$ caminho da servidão, de Friedrich Hayek (2010), no ano de 1944. Contudo, diante do contexto de ascensão do Estado de Bem-Estar Social europeu e do New Deal norte-americano, evidencia-se o recuo político das teses neoliberais, que passam, através dos encontros bianuais a partir de 1947, a estabelecer premissas teóricas contrárias ao intervencionismo estatal na economia.

8 - "A uberização consolida a passagem do estatuto de trabalhador para o de um nanoempresário-de-si permanentemente disponível ao trabalho; retira-lhe garantias mínimas ao mesmo tempo que mantém sua subordinação; ainda, se apropria, de modo administrado e produtivo, de uma perda de formas publicamente estabelecidas e reguladas do trabalho" (ANTUNES, 2018, p. 33 - grifos do autor).

9 - Segundo Marx (1985), isto significa a ampliação do investimento no capital constante em oposição ao capital variável, impulsionando a extração da mais-valia relativa sobre o proletariado diante do incremento tecnológico, em concomitância à redução do custo do trabalho com a consecutiva redução da demanda de dispêndio fisiológico. Isso além de acarretar a impossibilidade de transmutação em larga escala de trabalho simples para o trabalho complexo, desfaz progressivamente o caráter ontológico do capitalismo para a continuidade de seu circuito, pois a modernização de cunho técnico-científico despende o acréscimo do valor da força de trabalho, ameaçando a taxa de mais-valia, e consecutivamente a ampliação da superexploração e o próprio valor da mercadoria em si. Essa tendência, quando tomada pela universalidade corporativa leva a redução conjuntural da taxa de lucro pela incapacidade do capital constante em gerar mais-valia e não valorizar o capital. 
10 - Vasapollo (2005, pp. 29-33 - grifos do autor) destaca o trabalho interino, os trabalhos socialmente úteis, as bolsas de trabalho, os contratos temporários, o outsorcing, o staffleasing, o part-time, além da integração entre o trabalho e a aprendizagem.

11 - Dentre elas destacamos o colaborador, que "não têm, em comum, qualquer tipo específico de profissão, mas ao contrário, realizam trabalhos os mais variados. A sua diversidade também é responsável pela disparidade de remuneração" (VASAPOLLO, 2005, p. 39). Em dados comparativos, no caso europeu, o autor citado ressalta que que essa categoria aloca $41 \%$ dos jovens até 24 anos, que recebem em média três mil euros anuais. Sua volatilidade é brusca, assim como seu rendimento, que em muitos casos fica restrito aos lucros da empresa, que o responsabiliza e o penaliza caso não ocorra.

12 - "O ideário da "responsabilidade social corporativa" busca incorporar os conteúdos progressistas dos movimentos sociais da década de 1980-90. Tais conteúdos, como a defesa da cidadania, da participação popular e do controle social, são transmutados, refuncionalizados e destituídos de seus componentes mais críticos, em prol de uma sociabilidade "harmoniosa", do desenvolvimento sustentável e da união de esforços diferenciados no combate à pobreza” (CESAR, 2008, p. 31). Para tal, se distancia da ideia de caridade, para se aproximar da noção de cidadania, acrescida pelo adjetivo solidário.

13 - Isto ocorreu em diferentes escalas tendo por base o Índice de Desenvolvimento da Educação Básica (IDEB), articulando principalmente os indicadores de desempenho e os indicadores de fluxo escolar, levando diferentes sistemas de ensino estaduais à implementação da responsabilização docente e das medidas de bonificação conhecidas comumente como meritocracia. Destacamos também a ofensiva sobre a atuação docente tanto em sua responsabilização e enquadramento "cartesiano" vide o Método de Stallings (BANCO MUNDIAL, 2014), que resulta também no conteúdo meritocrático, quanto na restrição de sua autonomia pedagógica através do neoconservadorismo e da sua proletarização (OLIVEIRA, 2004).

14 - Destacamos aqui o Sistema de Avaliação da Educação Básica (SAEB), o Exame Nacional do Ensino Médio (ENEM) e o Exame Nacional de Desempenho dos Estudantes (ENDADE).

15 - Ver: https://brasil.elpais.com/brasil/2019/08/06/politica/1565115205_330204.html

16 - "A lógica da qualificação desenvolveu o modelo de carreira, em que a trajetória profissional era enquadrada nos parâmetros de classificação, correspondentes aos conjuntos de postos reunidos por similaridade técnica. A progressão ao seio de uma carreira obedecia a regras que se aplicavam, particularmente nas grandes empresas, combinadas à antiguidade e à seleção apoiada sobre critérios objetivos. [...] Sob a égide da autonomia requerida pelos processos automatizados, as formas de gestão do trabalho fazem incidir sobre os próprios trabalhadores a responsabilidade por gerar condições de promoção" (RAMOS, 2001, p. 63). Ou seja, procedimentos endógenos à lógica gestão por competência.

17 - Ver Harvey (1993), Sennett (2006) e Jameson (2006).

18 - Termo comumente utilizado nos documentos oficiais após a década de 1990.

\section{Referências bibliográficas}

AFONSO, Almerindo Janela. Avaliação educacional: regulação e emancipação: para uma sociologia das políticas avaliativas contemporâneas. São Paulo: Cortez, 2000.

AGAMBEN, Giorgio. Estado de exceção: [Homo Sacer, II, I]. São Paulo: Boitempo, 2015.

ALVES, Giovanni. Trabalho e subjetividade: o espírito do toyotismo na era do capitalismo. São Paulo: Boitempo, 2011.

ANDERSON, Perry. Balanço do neoliberalismo. In: SADER, Emir; GENTILI, Pablo (Orgs.). Pós-neoliberalismo: as políticas sociais e o Estado. Rio de Janeiro: Paz e Terra, 1995.

ANTUNES, Ricardo. O caracol e sua concha: ensaios sobre a nova morfologia do trabalho. São Paulo: Boitempo, 2005.

Adeus ao trabalho?: ensaios sobre as metamorfoses e a centralidade do mundo do trabalho. São Paulo: Cortez, 2011.

O privilégio da servidão: o novo proletariado de serviços na era digital. São Paulo: Boitempo, 2018.

BANCO MUNDIAL. Professores excelentes: como melhorar a aprendizagem dos estudantes da América Latina e Caribe. Washington: Banco Mundial, 2014.

BRASIL. Ministério da Educação. Base Nacional Comum Curricular. Brasília: MEC, 2018. CASTELO, Rodrigo. O social liberalismo: auge e crise da supremacia burguesa na era neoliberal. São Paulo: Expressão Popular, 2013. 
CESAR, Monica de Jesus. "Empresa-cidadã": uma estratégia de hegemonia. São Paulo: Cortez, 2008.

CHESNAIS, François. A mundialização do capital. São Paulo: Xamã, 1996.

COUTO, Marcos Antônio Campos. Base nacional comum curricular - BNCC componente curricular: geografia. Revista da ANPEGE, v. 12, n. 19, p. 183-203, 2016.

GRAMSCI, Antonio. Cadernos do Cárcere, volume 4: temas de cultura, ação católica. Americanismo e fordismo. 5. ed. Rio de Janeiro: Civilização Brasileira, 2015.

HOBSBAWN, Eric. Era dos Extremos: o breve século XX: 1914-1991. São Paulo: Companhia das Letras, 1995.

LACOSTE, Yves. A geografia-isso serve, em primeiro lugar, para fazer a guerra. São Paulo: Papirus, 1989.

MARX, Karl. O capital: crítica de economia política. São Paulo: Nova Cultural, 1985.

MARX, Karl; ENGELS, Friedrich. Manifesto comunista. Boitempo Editorial, 2015.

MÉSZÁROS, Ístvan. A crise estrutural do capital. São Paulo: Boitempo, 2011.

MOREIRA, Ruy. A diferença e a Geografia: o ardil da identidade e a representação da diferença na geografia. GEOgraphia, v. 1, n. 1, p. 41-58, 1999.

MARTINS, André Silva; NEVES, Lúcia Maria Wanderley. Educação Básica: tragédia anunciada? São Paulo: Xamã, 2015.

NEVES, Lúcia Maria Wanderley (Org.). A nova pedagogia da hegemonia: estratégias do capital para educar o consenso. São Paulo: Xamã, 2005.

OLIVEIRA, Dalila Andrade. A reestruturação do trabalho docente: precarização e flexibilização. Educação \& Sociedade, v. 25, n. 89, 2004.

PORTELLI, Hugues. Gramsci e o bloco histórico. Rio de Janeiro: Paz e Terra, 1977.

POULANTZAS, Nico. As classes sociais no capitalismo de hoje. Rio de Janeiro: Editora Zahar, 1978.

RAMOS, Marise Nogueira. A pedagogia das competências: autonomia ou adaptação. São Paulo: Cortez, 2001.

RAVITCH, Diane. Vida e morte do grande sistema escolar americano: como os testes padronizados e o modelo de mercado ameaçam a educação. Porto Alegre: Editoria Sulina, 2011. ROCHA, Genylton Odilon Rêgo da. O Ensino de Geografia no Brasil: as prescrições oficiais em tempos neoliberais. Revista Contrapontos, v. 10, n. 1, p. 14-18, 2010.

SCHNEIDER, Marilda Pasqual; NARDI, Elton Luiz. O IDEB e a construção de um modelo de accountability na educação básica brasileira. Revista Portuguesa de Educação, v. 27, n. 1, 2014.

SOUZA, José dos Santos. Trabalho, educação e sindicalismo: anos 90. Campinas, São Paulo: Autores Associados, 2002.

Mediação entre a escola e o novo mundo do trabalho na formação de técnicos de nível médio. Trabalho, Educação e Saúde, v. 16, n. 1, p. 123-140, 2018.

SOUSA NETO, Manuel Fernandes de. A Ágora e o Agora. Revista Terra Livre, n. 14, 1999. TONET, Ivo. Educar para a cidadania ou para a liberdade? Perspectiva, v. 23, n. 2, p. 469-484, 2005. 